\title{
INFLUENCE OF GIRDLING ON THE SEASONAL LEAF NUTRITION STATUS AND FRUIT SIZE OF ROBINSON MANDARIN (CITRUS RETICULATA BLANCO)
}

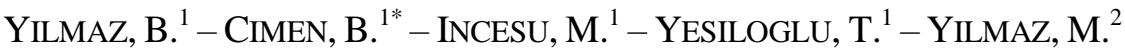 \\ ${ }^{I}$ Department of Horticulture, Faculty of Agriculture, Cukurova University \\ O1330 Adana, Turkey \\ ${ }^{2}$ Department of Horticulture, Faculty of Agriculture, Ordu University \\ 52200 Ordu, Turkey \\ *Corresponding author \\ e-mail: bcimen@cu.edu.tr; phonelfax: +90-322-338-6388 \\ (Received $18^{\text {th }}$ Jul 2018; accepted $22^{\text {nd }}$ Aug 2018)
}

\begin{abstract}
This study was undertaken to investigate the effects of single and double girdling applications on the fruit yield, commercial size, quality, photosystem II (PSII), leaf chlorophyll and leaf nutrition content of 22-year-old Robinson mandarin (Citrus reticulata). Girdling treatments were performed at anthesis (when $60 \%$ of the flowers were opened) with approximately $5 \mathrm{~mm}$ trunk diameter in 2014. The fruit was harvested in 2014 at the optimum harvest time (in December) for fruit yield, properties and size. Evaluations of leaf mineral content, chlorophyll concentration and fluorescence measurements were performed at monthly intervals. Leaf samples were taken in eight periods for analysis of plant nutri-elements. It was determined that double girdling was the best application in terms of fruit yield and percentage of marketable fruit. The treatments did not significantly affect fruit internal quality. Girdling reduced PSII and leaf chlorophyll concentration but did not affect leaf mineral content. However, we observed a tendency toward a decrease in nitrogen levels in the girdled trees. According to the results of the present study, girdling treatments significantly affected fruit yield and size together with several macro-micro plant nutri-elements.
\end{abstract}

Keywords: citrus, chlorophyll concentration, fruit yield, cultural practices, plant nutri-elements

\section{Introduction}

Due to the steady increase in citrus production in Turkey, 3,781,359 million tons of citrus fruits were produced in 2014. Of the citrus produced in Turkey, 1,779,675 tons were oranges (FAO, 2015). The main varieties of mandarin (Citrus reticulata) grown in Turkey are satsumas, such as 'Okitsu Wase',' Owari' and 'Dobashi Beni'; the rest include 'Nova', 'Robinson', 'Fremont', Clementine 'Murcott' and 'Minneola' (Tuzcu et al., 2001). Robinson is an early-ripening mandarin cultivar with high fruit quality; this variety is also productive and has low tendency for alternate bearing. However, fruit size in the citrus fruit market is very important, and small fruit size is one of the main factors limiting the sales of citrus fruit; large fruits bring higher prices in the export market. Consumers prefer large fruits; thus, there is a significant price difference between large and small fruits (Agustí et al., 1994; Guardiola and García Luis, 2000; Erner et al., 2004). In terms of determining profitability, the size of citrus fruit has become as important as the yield. This phenomenon is readily apparent for small mandarin fruits as well as lemons, sweet oranges and large grapefruit species (Guardiola and García Luis, 2000). Fruit size is affected by many factors, including irrigation management, soil type, rootstock, as well as ecological variables that cannot be controlled by the producer. Moreover, fruit size is inversely proportional to yield and fruit number (Guardiola, 1997). Bevington (2003) demonstrated that region, cultivar, rootstock, soil type, microecology 
and plant age all affect fruit size. The availability of carbohydrates (increases fruit size), flower intensity (decreases fruit size), competition between flowers/fruitlets (decreases fruit size) and abiotic stressors (decrease fruit size) are the most important factors affecting the final size of citrus fruits (Guardiola et al., 1982; Patrick, 1993; Agustí et al., 1995; Goldschmidt and Koch et al., 1996; El-Otmani et al., 2000). Cultural treatments such as pruning, irrigation and fertilization can be optimized to increase fruit size. For instance, techniques such as girdling (Cohen, 1984) and thinning (Hirose, 1981; Wheaton, 1981; Zaragoza et al., 1992; Guardiola and García Luis, 2000) are used in citrus production to increase fruit size.

Girdling applications are important and have been used worldwide for centuries in citrus and other fruit tree crops, especially to increase flowering, fruit set and fruit size (Tuzcu et al., 1992; Mostafa and Saleh, 2006). Girdling consists of the removal of a strip of bark from the trunk or major limbs of a fruit tree, which blocks the downward translocation of photosynthates and metabolites through the phloem, thus reducing fruit drop and enhancing fruit growth and yield (Zhao et al., 2013; Raveh, 2013; Mostafa and Saleh, 2006). Girdling applications at different times are used to increase the yield of fruit in some varieties, such as Robinson, Nova, Dancy, Osceola, Klemantin, Minneola, Orlando and Ortanique, which are self-sterile. The fruit set process is complex because photosynthetic activity and, thus, the production of photosynthetic compounds, can be altered by sink demand. Girdling effect has been related to the accumulation of photoassimilates in the canopy as a result of the interruption of the downward transport of soluble sugars resulting increases in fruit set in Citrus (Rivas et al., 2007). It has been reported that girdling treatments increased yield by $125 \%$ in mandarins (Rivas et al., 2006).

Girdling has also been shown to alter the partitioning of photosynthates, mineral nutrients and plant growth regulators in the tree (Rivas et al., 2006). On the upper line of girdling, leaf nitrogen $(\mathrm{N})$ content and Carbon $(\mathrm{C}) / \mathrm{N}$ ratio are improved, and as a result, flowering and fruit set are increased (Mostafa and Saleh, 2006). However, the effects of girdling on the translocation of various mineral nutrients in leaves are still unclear (Wang et al., 2010). Exactly how girdling functions in this way is still unknown, but the immediate effect of this technique is to break the phloematic flow toward the roots, thereby modifying the nutritional and hormonal balance of the plant (Vaio et al., 2001). In addition to single girdling, double girdling had, in most cases, a much greater effect than a single girdle. The greater efficiency of the double girdling may be due to this treat- ment keeping the girdling wound open for longer than with single girdles (Cohen, 1984).

The aim of this work was to study the effects of girdling on yield, fruit size and quality in the Robinson mandarin. Another objective was to determine the effects of trunk girdling on the quantum yield efficiency of PS II and the mobility of the mineral elements in Robinson mandarin leaves.

\section{Materials and methods}

\section{Plant materials}

The experiments were conducted on 22-year-old Robinson mandarin trees planted on sour orange rootstock at $6 \times 6 \mathrm{~m}$ intervals at the Research Station of Cukurova University, Agricultural Faculty Citrus Experiment Station, Adana, Turkey (latitude $35^{\circ} 23^{\prime} \mathrm{N}$; longitude $36^{\circ} 50^{\prime} \mathrm{E}$; altitude $27 \mathrm{~m}$ ) in 2016. The trees were managed and selected for uniformity and crop load. In the experimental area, the soil was clay loam (55\% clay, $22 \%$ silt and $23 \%$ sand containing $11 \% \mathrm{CaCO}_{3}$ ), and the soil $\mathrm{pH}$ was between 7.20 and 
7.29 at a depth of $0-90 \mathrm{~cm}$. The area has mean maximum and minimum temperatures of 26 and $14.5^{\circ} \mathrm{C}$, respectively, and an average annual rainfall of $465 \mathrm{~mm}$ (Fig. 1). The trees were irrigated weekly from May to October using drip irrigation. Nitrogen $(\mathrm{N})$ was applied at a rate of $1.5 \mathrm{~kg} \mathrm{~N} /$ tree (2/3 in mid-February and $1 / 3$ in mid-May), phosphorus (P) was applied at a rate of $1 \mathrm{~kg}$ P/tree (December), and potassium (K) was applied at a rate of $1 \mathrm{~kg} \mathrm{~K} /$ tree (January).

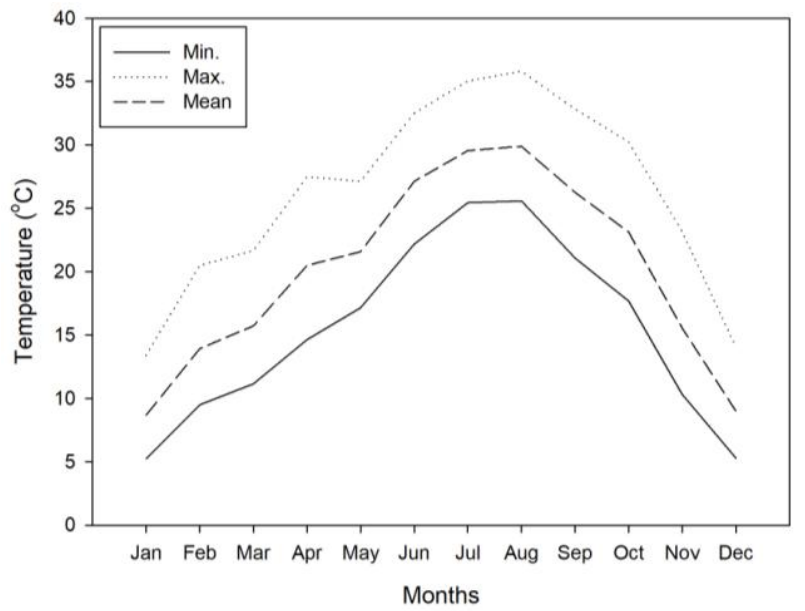

Figure 1. Minimum, maximum and mean temperature data of the experimental field in 2016

\section{Girdling treatments}

Girdling treatments were performed at anthesis (when $60 \%$ of the flowers were opened) with an approximately $5 \mathrm{~mm}$ diameter trunk using a girdling knife without injuring the wood layers. The experiment utilized a randomized complete block design with ten replicates for each treatment. Ten trees of each treatment were selected for similarity in size, vigor and flowering intensity. The girdling treatments were conducted on three plots with single girdling (SG), double girdling (DG) or without girdling (control). Single girdling (SG) was undertaken at $15 \mathrm{~cm}$ under the scaffold branch junction level. In the double girdling (DG) treatment, the first girdling was taken at $15 \mathrm{~cm}$ under the scaffold branch junction level and the second girdling at $5 \mathrm{~cm}$ above it (Fig. 2).
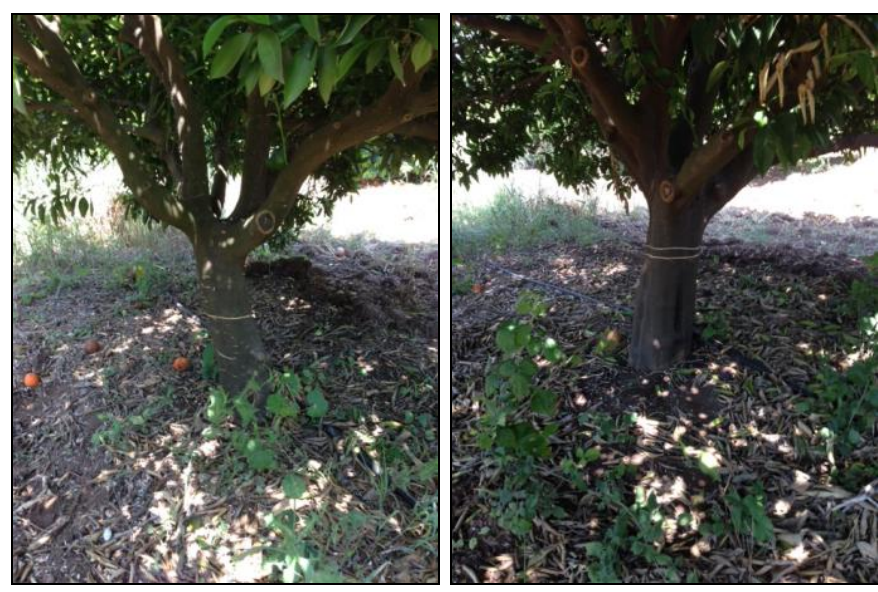

Figure 2. Single (left) and double (right) girdled 'Robinson' trees from examined orchard 


\section{Leaf chlorophyll concentration and photosystem II efficiency}

The leaf chlorophyll concentration was estimated using a portable SPAD meter (Minolta, Japan), and the chlorophyll fluorescence parameter $\left(\left(F v^{\prime} / F m^{\prime}\right)=\right.$ quantum yield in light-adapted leaves) was measured with a portable fluorometer (FluorPen FP100, Photon System Instruments Ltd, Drasov, Czech Republic). The evaluations of the chlorophyll concentration and fluorescence measurements were taken in six periods between 2015 and 2016. The same leaves were used to estimate the leaf chlorophyll (Chl) concentrations and PSII efficiency, based on the quantum yield of light-adapted leaves $\left(F v^{\prime} / F m^{\prime}\right)$, The chlorophyll concentration and maximum chlorophyll fluorescence efficiency readings for the light-adapted leaves were measured on 10 fully expanded young leaves (third and fourth leaves from the shoot apex) of each replicate at the four chosen time points. Measurements were performed before midday (08.00-11.00).

\section{Fruit yield, properties and size measurements}

The fruit was harvested in 2014 at the optimum harvest time (in December) from each plot. The yield per tree ( $\mathrm{kg} /$ tree) was obtained by weighing the harvested fruit. A random sample of 25 grapefruits was evaluated for rind thickness, percent juice, juice soluble solids (SSC), acidity and soluble solid/acid ratio. Fruits from each of the plots were measured at the fruit equatorial diameter and graded according to commercial categories as follows: >78 mm (extra), 71-78 mm (class 1), 65-70 mm (class 2), 59-64 mm (class 3), 53-58 mm (class 4), 47-52 $\mathrm{mm}$ (class 5) and <47 (discard). The 25 fruits were weighed and juiced using a standard juicer; then, the juice was weighed and expressed as a percentage of the total fruit weight. The fruit rind thickness was measured with a digital caliper (Mitutoyo CD-15CPX, Mitutoyo America Corporation, USA). Soluble solids were determined with a portable refractometer (FG-103/113) using a few drops of juice. The total acidity of the juice was determined by titrating $5 \mathrm{ml}$ of the juice sample with $0.1 \mathrm{~N}$ sodium hydroxide $(\mathrm{NaOH})$ using phenolphthalein as the indicator.

\section{Leaf chlorophyll concentration and fluorescence measurements}

The leaf chlorophyll concentration was estimated using a portable SPAD meter (Minolta, Japan), and the chlorophyll fluorescence parameter $\left(\left(F v^{\prime} / F m^{\prime}\right)=\right.$ quantum yield in light adapted leaves) was measured with a portable fluorometer (FluorPen FP100, Photon System Instruments Ltd, Drasov, Czech Republic). Evaluations of leaf mineral content, chlorophyll concentration and fluorescence measurements were initiated $15 \mathrm{~d}$ before girdling (in April) to ensure that there were no differences among trees at the beginning of the trial. Subsequent measurements were performed at monthly intervals as follows: $30 \mathrm{~d}$ after girdling (d.a.g) (in May), 60 d.a.g (in June), 90 d.a.g (in July), 120 d.a.g (in August), 150 d.a.g (in September), 180 d.a.g (in October), and 210 d.a.g (in November). Readings of chlorophyll concentration and maximum chlorophyll fluorescence efficiency in the light-adapted stage were measured on 10 fully expanded young leaves (third and fourth leaves from the shoot apex) of each replicate at the eight chosen time points. Measurements were performed before midday (08.00-11.00).

\section{Leaf mineral concentrations}

Leaf samples were taken at each of the eight time points for analysis of plant nutrielements in 2014 according to Chapman (1960). The leaves were washed in a detergent 
solution, rinsed several times in distilled water, and then dried at $70{ }^{\circ} \mathrm{C}$ for $48 \mathrm{~h}$ using a thermo-ventilated oven. The dried leaves were ground $(<0.5 \mathrm{~mm})$ and ashed in a muffle furnace at $550{ }^{\circ} \mathrm{C}$ for $8 \mathrm{~h}$. The ash samples were digested in $\mathrm{HNO}_{3}-\mathrm{HClO}_{4}(3: 1 \mathrm{v} / \mathrm{v})$ and filtered through a blue band paper filter (Kacar, 1972). In the extract solutions, sodium $(\mathrm{Na})$, potassium $(\mathrm{K})$, magnesium $(\mathrm{Mg})$, iron $(\mathrm{Fe})$, manganese $(\mathrm{Mn})$ and copper $(\mathrm{Cu})$ concentrations were determined by inductively coupled plasma-atomic emission spectrometry (ICP-AES, Varian Liberty Series II), and the concentrations of phosphorus (P) were determined by UV-VIS spectrophotometry (Barton, 1948). Leaf total nitrogen (N) content was determined by the semi-micro-Kjeldahl method (Less, 1971).

\section{Statistical analysis}

Data were subjected to two-way analysis of variance (ANOVA), and significant differences between means were evaluated using Tukey's multiple range test at $p \leq 0.05$ and $p \leq 0.01$. All statistical analyses were performed by using SAS v9.00 statistics software procedures (SAS, 2006), and SigmaPlot ${ }^{\circledR}$ version 11.00 was used for the data presentation.

\section{Results}

\section{Effects of girdling on fruit yield and fruit size}

The effects of girdling treatment on the distribution of the crop within the commercial fruit size classes were presented in Figure $3 \mathrm{~A}$.
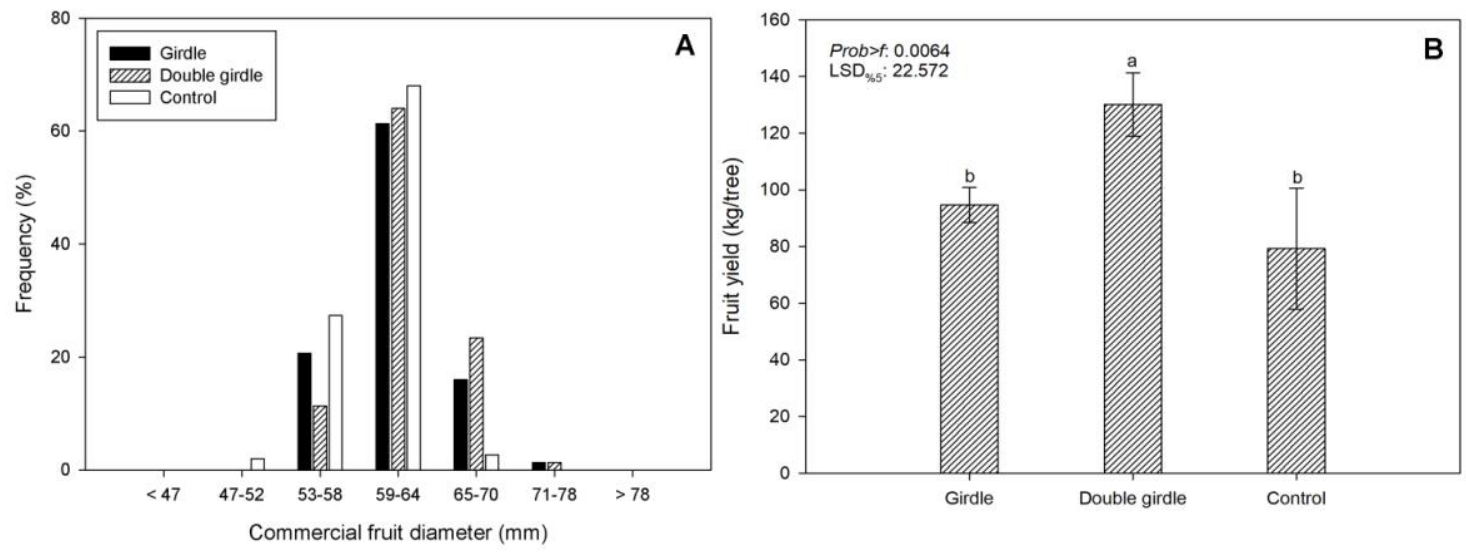

Figure 3. Effects of girdling treatments on the frequency distribution of the diameter (A) and fruit yield $(B)$ of the Robinson mandarin

The results indicated that the frequency distribution of the fruit shifted toward larger sizes when the trees were girdled. The highest percentage of large, commercially valuable Robinson fruits (71.00-78.00 $\mathrm{mm}$ and 65.00-70.00 $\mathrm{mm}$; classes 1 and 2, respectively) was obtained from trees with DG followed by those with SG. The control trees yielded no commercially valuable Robinson fruits $(71.00-78.00 \mathrm{~mm})$ and had the lowest percentage of large fruits (fruit sizes 65.00-70.00 mm). Moreover, compared with trees that were girdled, control trees produced a higher percentage of class 3 $(59.00-64.00 \mathrm{~mm})$ and class $4(53.00-58.00 \mathrm{~mm})$ fruits. Alternatively, the highest 
percentage of commercially unacceptable fruits $(47.00-52.00 \mathrm{~mm})$ was obtained from the control trees, even though in the girdled trees, there were no commercially unacceptable fruit sizes $(47.00-52.00 \mathrm{~mm}$ and $<47 \mathrm{~mm})$. Girdling treatments had a significant effect on the yield of Robinson mandarin (Fig. 3B). Compared with the controls, the girdling treatment led to an increase in the fruit yield. As shown in Figure $3 B$, the highest fruit yield per tree was obtained in the DG treatment followed by SG. Control trees produced a low yield compared with the treatment trees.

\section{Fruit internal quality}

Data in Table 1 show the effect of the girdling treatments on fruit internal quality in the Robinson mandarin. Girdling did not affect fruit internal quality, and no significant differences in the rind thickness, SSC content, acidity, SSC/acid ratio and juice content were observed. The girdling treatments decreased the rind thickness, although not significantly compared to the control. There were no trends observed for internal fruit quality due to girdling.

Table 1. Effects of girdling treatment on the rind thickness, total soluble solids (TSS), total acidity (TA), juice content and TSS/TA ratio

\begin{tabular}{c|c|c|c|c|c}
\hline Treatment & Rind thickness $(\mathbf{m m})$ & TSS $(\boldsymbol{\%})$ & TA $(\boldsymbol{\%})$ & Juice content $(\%)$ & TSS/TA \\
\hline SG & 4.37 & 11.27 & 0.96 & 49.42 & 11.92 \\
DG & 4.25 & 11.87 & 1.14 & 48.70 & 10.49 \\
Control & 4.60 & 11.87 & 1.01 & 47.74 & 11.72 \\
\hline Prob $>f$ & 0.6953 & 0.2014 & 0.2226 & 0.8058 & 0.2334 \\
\hline
\end{tabular}

\section{Leaf chlorophyll concentration and fluorescence measurements}

Girdling significantly affected the leaf chlorophyll (Chl) concentration. A two-way ANOVA indicated a significant main effect of girdling and sample date and of their interaction $(P \leq 0.01)$ on Chl concentration (Table 2).

Table 2. Results of two-way analysis of variance (ANOVA) testing for effects of sampling date $(S D)$ and girdling $(G)$ and their interaction $(S D \times G)$ on the dependent variables

\begin{tabular}{c|c|c|c}
\hline \multirow{2}{*}{ Dependent variable } & \multicolumn{3}{|c}{ Independent variable } \\
\cline { 2 - 4 } & SD & G & SD $\times$ G \\
\hline $\mathrm{N}$ & $15.44^{* * 1}$ & 1.31 & $2.06^{*}$ \\
$\mathrm{Fe}$ & $14.82^{* *}$ & 2.91 & $5.96^{* *}$ \\
$\mathrm{Cu}$ & 1.97 & 1.58 & 1.80 \\
$\mathrm{Mn}$ & $3.96^{* *}$ & 0.65 & 1.71 \\
$\mathrm{Mg}$ & $12.47^{* *}$ & 0.83 & $2.90^{* *}$ \\
$\mathrm{Na}$ & $4.45^{* *}$ & 0.39 & $2.12^{*}$ \\
$\mathrm{~K}$ & $5.42^{* *}$ & 2.01 & 1.51 \\
$\mathrm{P}$ & $7.16^{* *}$ & 1.13 & $2.50^{* *}$ \\
$\mathrm{PSII}$ & $16.09^{* *}$ & $5.11^{* *}$ & 0.90 \\
$\mathrm{SPAD}$ & $14.58^{* *}$ & $29.25^{* *}$ & $3.34^{* *}$ \\
\hline
\end{tabular}

${ }^{1}$ Numbers represent $F$ values. $* p \leq 0.05, * * p \leq 0.01$ 
Leaf chlorophyll concentrations ranged between 52.13 and 68.84 (Fig. 4A). The highest $\mathrm{Chl}$ concentration was obtained from the leaves of control plants, whereas the lowest was obtained from trees with SG followed by DG. In terms of Chl measurements, statistically significant differences were found between the sample time points. The lowest Chl was observed in June (60 d.a.g) and $15 \mathrm{~d}$ before girdling (in April). The highest Chl was found at 150 d.a.g (in September) (Fig. 4A). Girdling significantly affected on PSII efficiency in the Robinson mandarin (Table 2). A twoway ANOVA indicated a significant main effect of girdling and sampling time point $(P \leq 0.01)$. However, interactions were not observed between girdling treatment sampling points. In the present study, there was a tendency toward a decrease in PSII in girdled trees, especially in the DG treatment in comparison with controls. In terms of the PSII measurements, statistically significant differences were found between time points (Fig. 4B). The lowest chlorophyll fluorescence was observed in July (90 d.a.g) followed by $15 \mathrm{~d}$ before girdling (in April) and 30 d.a.g. (in May). The highest chlorophyll fluorescence levels were observed in October (180 d.a.g) and November (210 d.a.g).
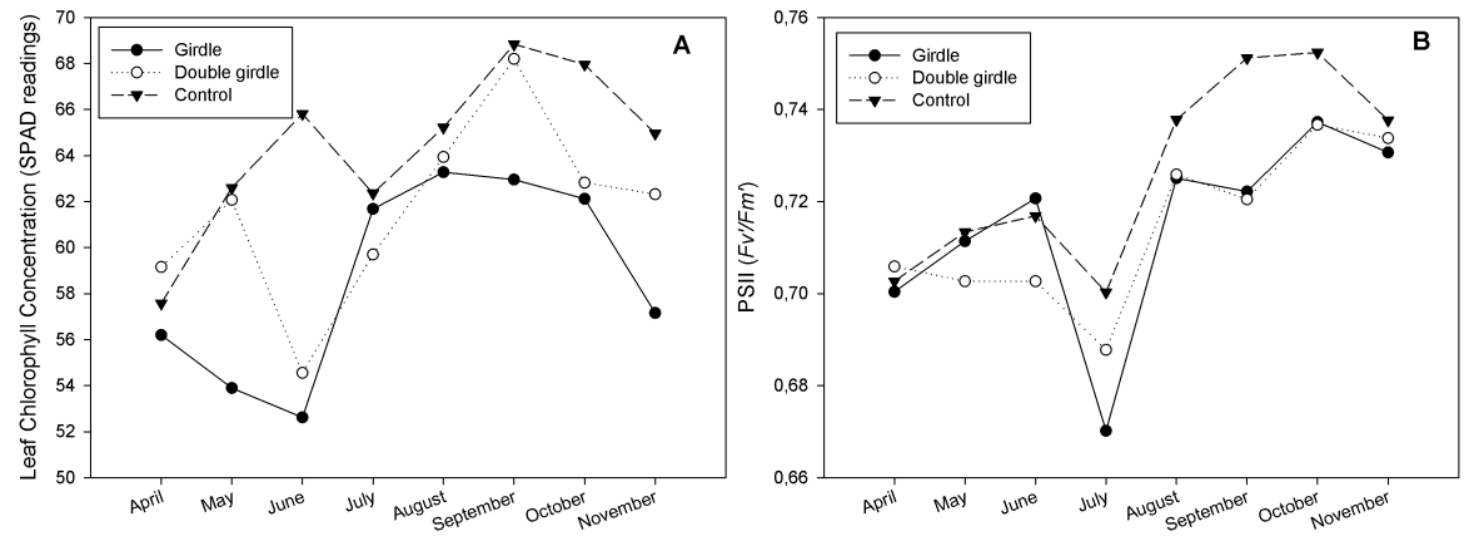

Figure 4. Effects of girdling treatments on the leaf chlorophyll concentration (A) and PSII efficiency $(B)$ in Robinson mandarins

\section{Leaf mineral concentrations}

In the present study, leaf mineral content was not affected by girdling treatment (Table 2). A two-way ANOVA indicated a significant effect of sample date and the interaction on the concentrations of some leaf minerals ( $\mathrm{N}, \mathrm{P}, \mathrm{Na}, \mathrm{Mg}, \mathrm{Fe}$ ) (Table 2). It can be argued that the significant differences among sample dates in mineral elements are a natural result because plant nutrients are used at different rates in different periods. Although not significantly, the leaf $\mathrm{N}$ levels were reduced in the girdled trees compared with non-girdled trees. There was a decrease in leaf $\mathrm{N}$ content until 30 d.a.g (in May) in girdled trees, while an increase was observed in untreated trees (Fig. 5A). In all treatments, a rapid increase was observed in the 60 d.a.g (June), but it was lower in girdled trees, especially after double girdling. The values of the control and girdled trees (except double girdling) showed a similar tendency after 120 d.a.g. (August) and remained more or less constant throughout the measurement periods. The potassium $(\mathrm{K})$ percentage in the leaves was not affected by any treatment (Fig. 5C). 

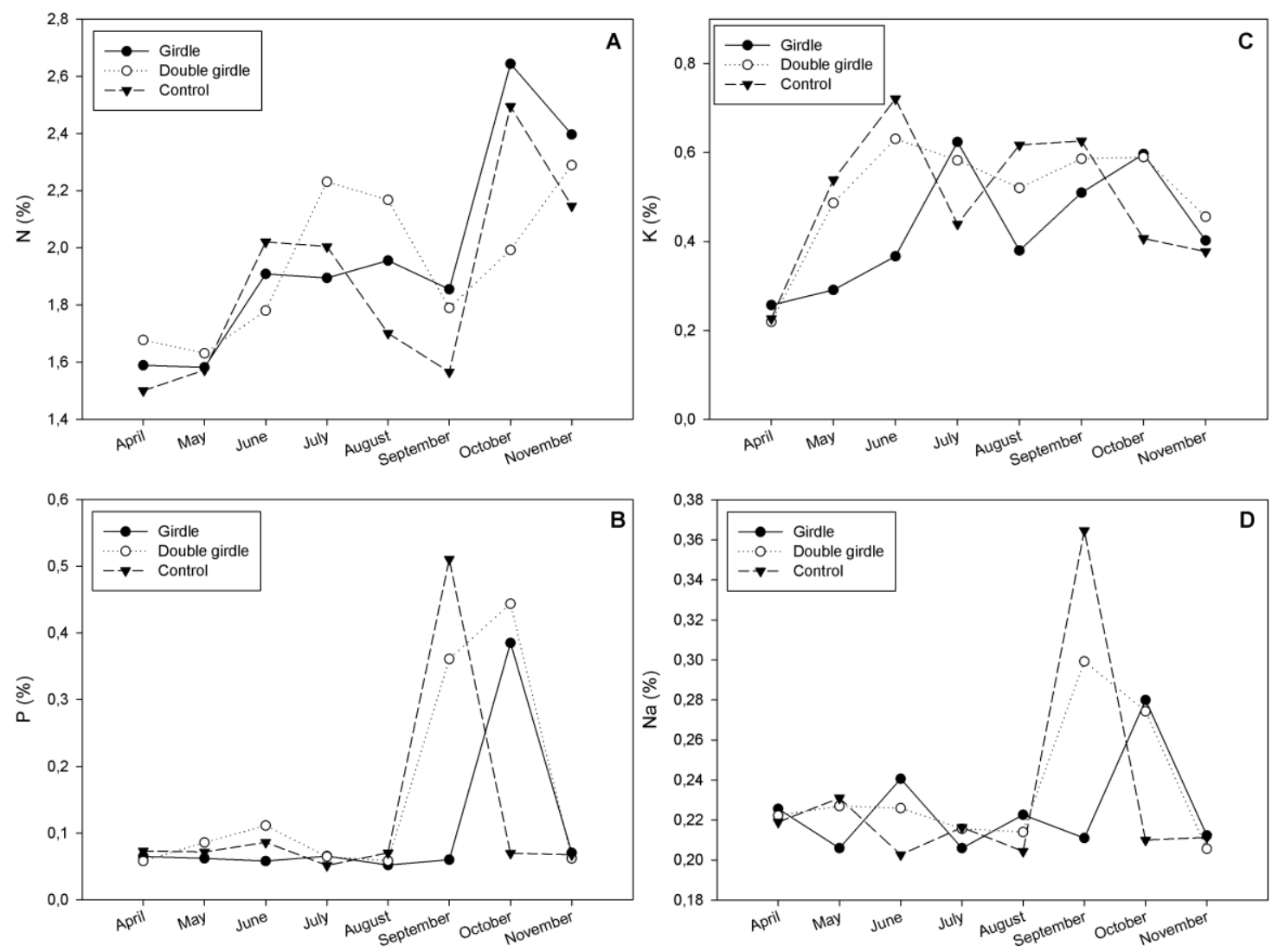

Figure 5. Effects of girdling treatments on the leaf $N(A), P(B), K(C)$ and $N a(D)$ concentrations in Robinson mandarins

The $\mathrm{K}$ value in the DG trees increased up to the 60 d.a.g (June) in all applications, though not as much as in the control trees. Similar trends were observed in other measurement periods in all treatments. Leaf $\mathrm{P}, \mathrm{Na}$ and $\mathrm{Mg}$ contents we not affected by the treatments and no trend was determined among the treatment in the different sample periods (Figs. $5 B-D$ and $6 A$ ). However, in terms of these values (P, $\mathrm{Na}$ and $\mathrm{Mg}$ ), a significant increase was observed in both control and girdled trees from the 120 d.a.g. (August), and these increases were more prominent in the control trees than in girdled trees. For all the measured micronutrients, similar trends were found (Fig. 6 A-D).

\section{Discussion}

According to the results obtained in this study, girdling application significantly affected fruit set, and the most effective treatment was DG followed by SG. The most favorable effect of girdling was the improvement of fruit set and growth, especially after DG treatment. In previous studies, a significant increase in the fruit yield of the Balady mandarin was obtained when a girdling treatment was applied before blossoming (Mostafa and Saleh, 2006). Additionally, according to Rivas et al. (2007), girdling delayed fruitlet abscission in all shoot types and leafy flowering shoots had increased fruit set in Loretina and Nova mandarin cultivars. According to Rivas et al. (2006), the productivity of Fortune and Clausellina mandarins can be improved by girdling. Moreover, Tuzcu et al. (1992) found that the application of double girdling at 
the beginning of flowering increases the yield of the Algerian tangerine (clementine/mandarin) compared to the control. Similarly, trunk girdling has been shown to increase fruit set in many crops, including apple (Malus domestica Borkh.) (Hoying and Robinson, 1992), lychee (Litchi chinensis Sonn.) (Roe et al., 1997), kiwifruit (Actinidia chinensis Planch.) (Boyd and Barnett, 2011) and Fuyu persimmon (Diospyros kaki L.) (Choi et al., 2010).
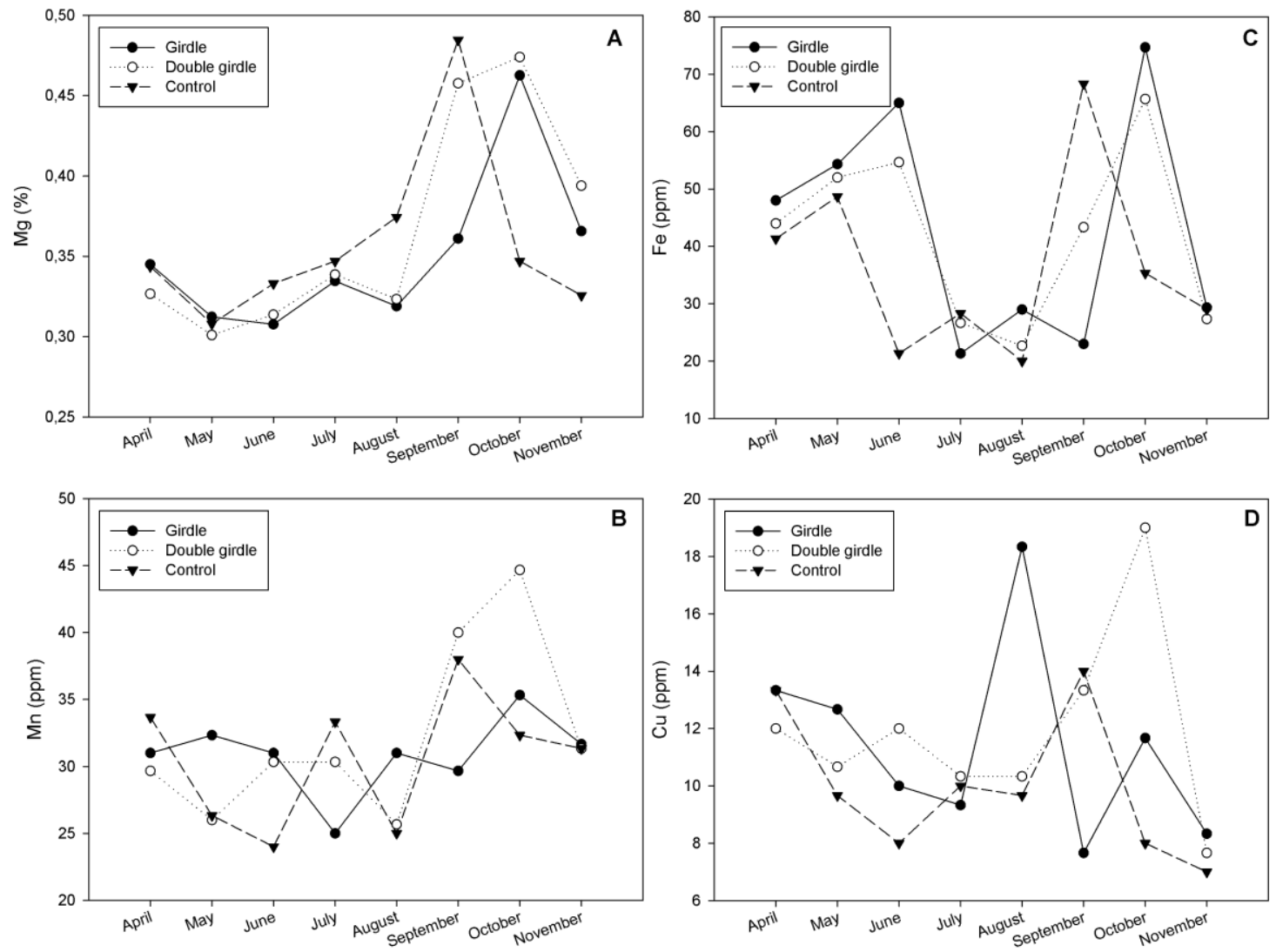

Figure 6. Effects of girdling treatments on the leaf $\mathrm{Mg}(A), \mathrm{Mn}(\mathrm{B}), \mathrm{Fe}(\mathrm{C})$ and $\mathrm{Cu}(\mathrm{D})$ concentrations in Robinson mandarins

Fruit size is one of the most important factors affecting the marketing of fresh citrus fruits. Thus, techniques such as girdling, thinning and synthetic auxin application are commonly used to increase the size of fruit for fresh consumption. Girdling applications often promote fruit set and increase the size of fruit. In addition, Agustí et al. (2002) demonstrated that girdling can be used to increase final fruit size. In the present study, fruit diameter was significantly affected by the application of girdling treatments. Specifically, treatment with girdling increased the number of large fruits and reduced the number of fruits with a diameter $<65 \mathrm{~mm}$. In previous studies, fruits harvested from trees treated with girdling were significantly larger than fruits from control trees, which indicated that the application of girdling increased fruit size (Tuzcu et al., 1992; Mostafa and Saleh, 2006; Rivas et al., 2007). Moreover, Cohen (1984) found that the application of summer girdling increased fruit size of the Marsh seedless grapefruit. Similarly, Khandaker et al. (2011) indicated that fruit size of wax jambu was 
significantly influenced by different girdling treatments and that girdled branches produced the highest fruit length and diameter compared to the control branches.

Girdling treatments resulted in no marked effects upon the fruit quality. The results obtained in the present study are in concordance with those of previous studies that reported that girdling increases SSC in navels (Church, 1993) and satsumas (Peng and Rabe, 1996). However, the increased SSC due to girdling was not always significant. The results obtained in the present study are in agreement with those described in a previous report by Verreynne et al. (2001), who studied the effects of trunk girdling on the internal fruit quality of the "Marisol" clementine and found no significant differences in fruit quality due to girdling. According to Peng and Rabe (1996), girdling did not have any significant effect on juice volume; however, Mostafa and Saleh (2006) reported lower juice volume after girdling. In addition, Roussos and Tassis (2011) demonstrated that the titratable acidity, $\mathrm{pH}$ and maturity index of the Nova mandarin were not significantly affected by girdling.

Our results demonstrate that girdling has a significant effect on the quantum yield of PSII $(F v / F m)$, especially with DG. In addition, the differences in PSII between girdled trees tended to decrease in comparison with controls. The results obtained in the present study are in agreement with those described in a previous report by Rivas et al. (2007), who studied the effects of girdling on fruit set and quantum yield efficiency of PSII in two Citrus cultivars and indicated that girdling reduced the quantum yield efficiency of PSII in the leaves of vegetative shoots. Similar results were reported in mango (Urban et al., 2004), and P. canariensis (López et al., 2015). Additionally, according to Quentin et al. (2013), leaves on girdled trees had a reduction of $A_{\text {net }}$ compared to leaves on control trees. Similar results have also been reported for wet tropical rainforest trees (Asao and Ryan, 2015). Similarly, no significant differences in photosynthetic activity between the control and girdled shoots were observed until the day after girdling. However, the photosynthesis activity of the control tree then increased until harvest, while the girdled shoots showed a significant reduction (Vaio et al., 2001). The most well-known effect of girdling is the increase in carbohydrates above the girdle (Fishler et al., 1983; Mataa et al., 1998; Urban et al., 2004). However, girdling reduces leaf net photosynthesis in numerous fruit trees (Inglesias et al., 2002; Zou and Quebedeaux, 2003; Urban et al., 2004; Frank et al., 2006). According to Quentin et al. (2013), the photosynthetic activity of leaves might be restricted by feedback control in the absence of adequate sinks or upregulated where sink demand is increased. Recent studies have shown that the decline in leaf net photosynthesis due to sink demand is independent of a direct feedback effect of the end products (DaMatta et al., 2008; Cheng et al., 2008). In addition, López et al. (2015) demonstrated that the accumulation of carbohydrate can explain the reduction in the quantum yield efficiency of photosystem II through feedback loops.

Regarding chlorophyll concentration in the leaves, we found that chlorophyll concentrations decreased in girdled plants. The values of the control trees increased continuously until 60 d.a.g (in June), while the girdled trees showed a marked decrease. The values of control and girdled trees showed a similar tendency after 90 d.a.g (July) and remained more or less constant throughout the measurement periods. The results obtained in the present study are in agreement with those described in a previous report by López et al. (2015), who studied the effects of stem girdling on photosynthesis and chlorophyll in $P$. canariensis and found that they progressively decreased in girdled plants but that the effect was rapidly reversed when the phloem was reconnected. Rivas et al. (2007) demonstrated that girdling had no effect on foliar Chl concentrations 
between control and girdled trees in two Citrus cultivars. In addition, Mostafa and Saleh (2006) indicated that all treatments significantly increased both total chlorophyll and $\mathrm{Ch}_{\mathrm{a}}$ compared to untreated trees, but no significant differences in leaf $\mathrm{Ch}_{\mathrm{b}}$ were detected among the treatments.

Our results showed that girdling did not affect leaf mineral content. However, we observed a tendency toward decrease in nitrogen level in the girdled trees. Similar trends were observed in the other measurement periods in all treatments. According to Cimó et al. (2013), girdling treatments decreased N, P, K, Ca and Mg concentrations in the leaves of citrus and reduced the levels of all measured micronutrients. Davies et al. (1995) reported that $\mathrm{N}, \mathrm{K}$ and Ca levels were lower in avocado leaves in girdled branches compared with those of control branches. Similarly, trunk girdling decreased $\mathrm{N}$ levels in the leaves of several crops, including lychee (Litchi chinensis Sonn.) (Wang et al., 2010) and pistachio (Pistacia vera L.) (Vemmos, 2005). Mostafa and Saleh (2006) also demonstrated that the $\mathrm{P}$ percentage in the leaves of the Balady mandarin was not affect by girdling. Moreover, Jasrotia et al. (2014) found that leaf N and P in olive were not affected by girdling.

\section{Conclusion}

In conclusion, girdling significantly increased fruit set; especially when girdling was performed at the onset of cell enlargement stage, it increased the final fruit size and improved the commercial fruit size distribution. According to our results, girdling treatments increased the yield and commercial fruit size of the Robinson mandarin variety so that the girdling as one of the cultural practices can be applied for higher fruit size and fruit yield. We determined that girdling has a significant effect on both the PSII and leaf chlorophyll concentration as both decreased in girdled trees. This decrease may be related to carbohydrate accumulation in upper site of the girdling zone as reported in previous studies.

\section{REFERENCES}

[1] Agustí, M., Almela, V., Juan, M., Primo-Millo, E., Trenor, I., Zaragoza, S. (1994): Effects of 3,5,6-trichloro-2-pyridyloxyacetic acid on fruit size and yield of clausellina mandarin (Citrus unshiu Marc.). - Jour. of Hort. Sci. 69(2): 219-223.

[2] Agustí, M., El-Otmani, M., Aznar, M., Juan, M., Almela, V. (1995): Effect of 3,5,6trichloro-2-pyridyloxyacetic acid on Clementine early fruitlet development and on fruit size at maturity. - J. of Hort. Sci. 70(6): 955-962.

[3] Agustí, M., Martinez-Fuentes, A., Mesejo, C. (2002): Citrus fruit quality. Physiological basis and techniques of improvement. - Agrociencia 2: 1-16.

[4] Asao, S., Ryan, M. G. (2015): Carbohydrate regulation of photosynthesis and respiration from branch girdling in four species of wet tropical rain forest trees. - Tree Physiology 35: 608-620.

[5] Barton, C. J. (1948): Photometric analysis on phosphate rock. - Ind. and Eng. Chem. Anal. Ed. 20: 1068-1073.

[6] Bevington, K. (2003): Optimisation of Citrus Production and Fruit Size: An Interactive Management Model. Fruit Size Management Guide Part I. - Australian Citrus Growers Publication, Mildura. 
[7] Boyd, L. M., Barnett, A. M. (2011): Manipulation of whole-vine carbon allocation using girdling, pruning, and fruit thinning affects fruit numbers and quality in kiwifruit. Hortscience 46: 590-595.

[8] Chapman, H. D. (1960): Leaf and Soil Analysis in Citrus Orchards, Criteria and Diagnosis of Management Practice. - Manuel Berkeley, California University of California Division of Agricultural Science, Berkeley.

[9] Cheng, Y., Arakawa, O., Kasai, M., Sawada, S. (2008): Analysis of reduced photosynthesis in the apple leaf under sink-limited conditions due to girdling. - J Jpn Soc Hortic Sci. 77: 115-121.

[10] Choi, S. T., Song, W. D., Park, D. S., Kang, S. M. (2010): Effect of different girdling dates on tree growth, fruit characteristics and reserve accumulation in a late-maturing persimmon. - Scientia Horticulturae 126: 152-155.

[11] Church, C. G. (1933): Composition of juice of oranges from girdled and normal trees. Calif. Citrogr. 18: 348-349.

[12] Cimò, G., Bianco, R. L., Gonzalez, P., Bandaranayake, W., Etxeberria, E., Syvertsen, J. P. (2013): Carbohydrate and nutritional responses to stem girdling and drought stress with respect to understanding symptoms of Huanglongbing in Citrus. - HortScience 48(7): 920-928.

[13] Cohen, A. (1984): Citrus fruit enlargement by means of summer girdling. - J. Hortic. Sci. 59: 119-125.

[14] Da Matta, F. M., Cunha, R. I., Antunes, W. C., Martins, S. C. V., Araujo, W. I., Fernie, A. R., Moraes, G. A. B. K. (2008): In field-grown coffee trees source-sink manipulation alters photosynthetic rates, independently of carbon metabolism, via alterations in stomatal function. - New Phytol. 178: 348-357.

[15] Davies, S. J., Stassen, P. J. C., Martie, W. (1995): Girdling for increased Hass fruit size and its effect on carbohydrate production and storage. - Proc. World Avocado Congress 3: $25-28$.

[16] El-Otmani, M., Coggins, C. W., Agustí, M., Lovatt, C. (2000): Plant growth regulators in citriculture: World current uses. - Critical Reviews in Plant Sciences 19: 395-447.

[17] Erner, Y., Tagari, E., Hamou, M., Katzir, I. (2004): Enhancing citrus fruit size: An overview of opportunities and achievements in Israel. - Proc. Int. Soc. Citriculture 2: 495-501.

[18] FAO (2015): Food and Agriculture Organization. The Database of Annual Production. FAOSTAT. Statistical database. http://faostat.fao.org.

[19] Fishler, M., Goldschmidt, E. E., Monselise, S. P. (1983): Leaf area and fruit size on girdled grapefruit branches. - J. Amer. Soc. Hort. Sci. 108(2): 218-221.

[20] Frank, N., Vaast, P., Génard, M., Dauzat, J. (2006): Soluble sugars mediate sink feedback down-regulation of leaf photosynthesis in field-grown Coffea Arabica. - Tree Physiol. 26: 517-525.

[21] Goldschmidt, E. E., Koch, K. E. (1996): Citrus. - In: Zamski, E., Schafer, A. A. (eds.) Photoassimilate Distribution in Plants and Crops. Source-Sink Relationships. Marcel Dekker, Inc., NewYork, pp.797-823.

[22] Guardiola, J. L. (1997): Increasing Citrus Fruit Size with Synthetic Auxins. - In: Futch, S. H., Kender, W. J. (eds.) Citrus Flowering and Fruiting Short Course. - Univ. of Florida, Lake Alfred, FL, pp. 79-86.

[23] Guardiola, J. L., Agustí, M., García-Marí, F., Almela, V. (1982): The regulation of fruit size in citrus by tree factors. - XXIst Int. Hortic. Congress 1: 1363.

[24] Guardiola, J. L., García-Luis, A. (2000): Increasing fruit size in Citrus. Thinning and stimulation of fruit growth. - Plant Growth Regulation 31: 121-132.

[25] Hirose, K. (1981): Development of chemical thinners for commercial use for satsuma mandarin in Japan. - Proc. of Int. Soc. of Citriculture 1: 256-260.

[26] Hoying, S. A., Robinson, T. L. (1992): Effects of chain saw girdling and root pruning of apple trees. - Acta Hortic. 322: 167-172. 
[27] Inglesias, D. J., Llsio, I., Tadeo, F. R., Talon, M. (2002): Regulation of photosynthesis through source: sink imbalance in citrus is mediated by carbohydrate content in leaves. Physiol. Plant. 116: 563-572.

[28] Jasrotia, A., Bakshi, P., Wali, V. K., Bhushan, B., Ji Bhat, D. (2014): Influence of girdling and zinc and boron application on growth, quality and leaf nutrient status of olive cv. Frontoio. - African J. of Agric. Res. 9(18): 1354-1361.

[29] Kacar, B. (1972): Chemical Analysis of Soil and Plant. - Ankara Univertisty Press, Ankara, Turkey.

[30] Khandaker, M. M., Hossain, A. B. M. S., Osman, N., Boyce, A. N. (2011): Application of girdling for improved fruit retention, yield and fruit quality in Syzygium samarangense under field conditions. - Int J of Agric \& Bio. 13: 18-24.

[31] Less, H. (1971): Laboratory Handbook of Methods of Food Analysis. - Leonard Hill Books, London.

[32] López, R., Brossa, R., Gil, L., Pita, P. (2015): Stem girdling evidences a trade-off between cambial activity and sprouting and dramatically reduces plant transpiration due to feedback inhibition of photosynthesis and hormone signaling. - Frontiers in Plant Sci. 6: 1-11.

[33] Mataa, M., Tominaga, S., Kozaki, I. (1998): The effect of time of girdling on carbohydrate contents and fruiting in Ponkan mandarin (Citrus reticulata Blanco). - Sci Hortic. 73: 203-211.

[34] Mostafa, E. A. M., Salah, M. M. S. (2006): Response of Balady mandarin trees to girdling and potassium sprays under sandy soil conditions. -Research J of Agric and Bio Sci 2(3): 137-141.

[35] Patrick, J. W. (1993): Sink strength: whole plant considerations. - Plant Cell and Environment 16: 1019-1020.

[36] Peng, Y. H., Rabe, E. (1996): Effect of summer trunk girdling on fruit quality, maturation, yield, fruit size and tree performance in Mihowase satsumas. - J. Hortic. Sci. 71: 581-589.

[37] Quentin, A. G., Close, D. C., Hennen, L. M. H. P., Pinkard, E. A. (2013): Downregulation of photosynthesis following girdling, but contrasting effects on fruit set and retention, in two sweet cherry cultivars. - Plant Physiology and Biochemistry. 73: 359367.

[38] Raveh, E. (2013): Girdling for Crop Regulation. - Citrus Growers Technical Conference \& Workshop, Dareton.

[39] Rivas, F., Erner, Y., Alós, E., Juan, M., Almela, V., Agustí, M. (2006): Girdling increases carbohydrate availability and fruit set in citrus cultivars irrespective of parthenocarpic ability. - Journal of Hort. Sci. \& Biotechnology 81(2): 289-295.

[40] Rivas, F., Gravina, A., Agustí, M. (2007): Girdling effects on fruit set and quantum yield efficiency of PSII in two Citrus cultivars. - Tree Physiol. 27: 527-535.

[41] Roe, D. J., Menzel, C. M., Oosthuizen, J. H., Doogan, V. J. (1997): Effects of current $\mathrm{CO} 2$ assimilation and stored reserves on lychee fruit growth. - J. Hortic. Sci. 72: 397405.

[42] Roussos, P. A., Tassis, A. (2011): Effects of girdling, nitrogen, zinc and auxin foliar spray applications on mandarin fruit Nova quality characteristics. - Emir J Food Agric 23(5): 431-439.

[43] Tuzcu, O., Kaplankıran, M., Yeşiloğlu, T. (1992): Effects of girdling applications on fruit yield and fruit size in Clementine mandarin. - Proc. Int. Soc. Citriculture 2: 735-739.

[44] Tuzcu, Ö., Yeşiloğlu, T., Yıldırım, B. (2001): Citrus 2001 Reports: Turkey. - Florida Grower Annual Edition, Mid-August 2001, pp. 25-26.

[45] Urban, L., Lechaudel, M., Lu, P. (2004): Effect of fruit load and girdling on leaf photosynthesis in Magnifera indica L. - J. of Experimental Botany 55(405): 2075-2085.

[46] Vaio, C. D., Petito, A., Buccheri, M. (2001): Effect of girdling on gas exchanges and leaf mineral content in the independence nectarine. - J of Plant Nutrition 24(7): 1047-1060. 
[47] Vemmos, S. N. (2005): Effects of shoot girdling on bud abscission, carbohydrate and nutrient concentrations in pistachio (Pistacia vera L.). - The Journal of Hort. Sci. and Biotech. 80(5): 529-536.

[48] Verreynne, J. S., Rabe, E., Theron, K. I. (2001): The effect of combined deficit irrigation and summer trunk girdling on the internal fruit quality of Marisol Clementines. - Scientia Horticulturae 91: 25-37.

[49] Wang, L., Wang, H., Li, J., Huang, X. (2010): Effects of branch girdling on shoot growth and mineral nutrients in Litchi. - Journal of Fruit Sci. 27: 2.

[50] Wheaton, T. A. (1981): Fruit thinning of Florida mandarins using plant growth regulators. - Proc. Int. Soc. Citriculture 1: 263-268.

[51] Zaragoza, S., Tenor, I., Alonso, E., Primo Millo, E., Agustí, M. (1992): Treatments to increase the final fruit size on Satsuma Clausellina. - Proc. Int. Soc. Citriculture 2: 725728.

[52] Zhao, Y., Zhang, L., Gao, M., Tian, L., Zheng, P., Wang, K., Zhang, L., Li, B., Han, M., Alva, A. K. (2013): Influence of girdling and foliar applied urea on apple (Malus domestica L.) fruit quality. - Pak. J. Bot. 45(5): 1609-1615.

[53] Zou, R., Quebedeaux, B. (2003): Changes in photosynthesis and carbohydrate metabolism in mature apple leaves in response to whole plant source-sink manipulation. J. Ame. Soc. Hortic. Soc. 128: 113-119. 